\title{
The place of Zeno's paradox
}

\section{Laurence Paul Hemming}

Department of Organisation, Work and Technology, Lancaster University Management School, Lancaster LA1 4YX, England; e-mail: laurence.hemming@btinternet.com

Received 22 June 2010; in revised form 24 December 2010

\begin{abstract}
This paper begins by examining the recent history of interpretations of one of Zeno's paradoxes of motion, the paradox of dichotomy. It then returns to the record of antiquity to ask how Aristotle 'solved' the paradox and what decisions about place and motion were assumed in that solution. After appealing to Heidegger's readings of the Aristotelian text, the paper then proceeds to offer an entirely original interpretation of Zeno's paradox of dichotomy, which has important implications for a contemporary understanding of motion and place (rather than space). Instead, the paradox is read as a provocation to 'see' something which Zeno, it would appear, believed was 'missing', or had been forgotten and had disappeared, and to review all over again what Parmenides might have meant in his claim that being is one, singular, and indivisible.
\end{abstract}

\section{Introduction}

Zeno, disciple of the Eleatic philosopher Parmenides, leaves to history a series of paradoxes that have either perplexed or excited the disdain of philosophers ever since. No text of Zeno's survives for us to consult: our knowledge of the paradoxes themselves is drawn almost entirely from Aristotle's Physics and Metaphysics and from the writings of Simplicius. Hermann Diels summarises the fragmentary discussions of Zeno, together with references to lost works and extant citations from Aristotle, Simplicius, Diogenes Laertius, and others in Diels (1922). Plato's discussions of Zeno are of a different order, more preoccupied with Zeno's relation to Parmenides (although his are the only authority that we have for the relation that he claims). In the Phaedrus Zeno appears named by Socrates as the "Eleatic Palamedes" (Plato, Phaedrus 261 D). Recent scholarship has opened up the question of whether the relation is fictitious, a conceit of Plato's invention: see Solmsen (1971) and Vlastos (1975).

A history of the paradoxes in subsequent commentary can be found in Cajori (1915, pages $\mathrm{i}-6,39-47,77-82,109-115,143-149,179-186,215-220,253-258,292-297$; and see Cajori, 1920). Cajori is forced to conclude from all of his researches that "lack of detailed information on the exact nature of Zeno's arguments leads to a drawn battle" (1915, page 19). Lee (1936) attempts to provide a text and commentary on all the significant passages which arrive from posterity concerning Zeno. More recent discussions of the paradoxes abound, but for just some see: Booth (1957), providing a solid survey of the recent Anglophone and French literature to that date; Quan (1968), written in a style all too characteristic of a certain type of analytic philosophy of the time, resorting to accusations of "mental confusion" (page 219) and "fundamental mistake" (page 220) whenever the paradox cannot be hammered into a shape suitable for the sharp-witted modern philosopher to 'solve' it; and Sherry (1988) whose discussion distinguishes itself by managing to refer to Aristotle constantly, refering to his text only once (page 71), even then by not quoting a single word of Aristotle's either in Greek or in translation. A rare Anglophone attempt to take seriously the metaphysical concern for unity in the paradoxes is Papa-Grimaldi (1996). 
If his most famous is the paradox of Achilles and the tortoise, its cousin, similar in nature, is often called the paradox of dichotomy. The paradox draws its name from the Greek verb dichotomeo (to divide into two), and it states that in setting out in any way you will never arrive because before you can get to where you want, you must travel half the way there, and before you can reach halfway you must reach half of the halfway (a quarter) and before that half again (an eighth), and so forth. You can never set out for where you want to go because between you and where you are going is an infinite (endless, indeterminate) series of pairs of dichotomies-divisions into two, each half of the last, which you must first traverse. To attempt to move is to be fixed still in the very attempt.

Taken at the most immediate, it is obvious that the paradox attempts to address the question of unity by exhibiting a peculiarity of the character of motion. In stating this, however, one manages to say almost nothing of any significance at all. The argument of this paper is that the paradox intends to bring to the fore phenomena that arise precisely on the basis of their no longer adequately being taken for granted: the paradox is striving to bring them before us as a riddle and in the very act of pressing on us the perplexity of the insolubility of the paradox itself. In the historical discussion only very rarely do any of the commentators come close to uncovering this aspect of the paradox, and none unravel the riddle. The absent phenomena in question are twofold. First is the phenomenon that Heidegger once referred to as the 'cointention', 'saying-with' (Mitsagen) of 'copresence' (Mitgegenwärtige)—what in all saying of something is always intended to be said 'alongside and with' whatever is said. Heidegger (1992, pages 507-574) discusses the mit- character of 'co'intention, saying, and presence in full in, but for the clearest definition see Heidegger (1992, page 515), where he says that for Plato, "they need only to speak to indicate that in all speaking, all addressing of something, there are determined structures cointended by what is being said".(1) In this sense the unsaid is always said alongside the said. The essential understanding of modern writing, especially philosophical writing, takes for granted that 'saying and meaning are the same', with all the attendant problems that brings. These are normally tackled through the merely subjectival resolutions of irony, intention, textuality, and so forth. At one point Heidegger shows how Plato appeals to the sense of the Greek word apidein, 'looking away'. He comments, "Certainly, if 'looking-away' is taken in the sense of 'not-looking-at', then it would seem that for all eternity we could not work out how something might be seen here. But this apidein does not mean looking-away, but drawing-out in seeing from the already-given, and going out after what is seen in the drawn-out" (Heidegger, 1992, page 494). (2)

In this discussion Heidegger shows how, for Plato, the question of what is 'seen' in the drawing-out is 'being'. Being, as he states elsewhere in the same discussion (of Plato's Sophist), is always what is cointended in all saying: specifically (for our purposes here with Zeno), the unity of being. However, as Heidegger was later to emphasise ever more strongly, 'being' for Plato is already displaced to the 'over-there' or 'beyond' of being, in a way that Hegel and Nietzsche, and the thinking that followed them, all were later to struggle against and fiercely. The argument here is that Zeno's paradox speaks of the point of that displacement: both acknowledging it, and challenging it at the same time. The paradox is therefore primarily not a reference to the

(1) "Sie brauchen nämlich nur zu sprechen, dann zeigt sich, daß in jedem Sprechen, jedem Ansprechen von etwas, bestimmte Strukturen des Gesagtseins mitgemeint sind."

(2) "Wenn man freilich 'absieht' nimmt im Sinne des Nicht-Hinsehens, dann ist wahrscheinlich in alle Ewigkeit nicht auszumachen, wie man da etwas sehen soll. Aber dieses á $\pi \_\delta$ IIv heißt nicht: wegsehen, sondern: heraussehen aus dem Vorgegebenen und dem Herausgesehenen nachgehen." 
cointention of the displaced understanding of being, but has the power, if we read it aright, to show how being and place belong together: how place speaks of being.

The second phenomenon at issue in the paradox is not, therefore, place as such but the relationship to place that actually lets cointention appear as a phenomenon at all. When we speak of 'relationship to place', we are all too apt to hear this in the modern sense: place is somewhere I 'step into' when I open the front door of thinking and set out. 'Place' - as something always to be recovered, to be got to, and to be got at by clever, adequate, genealogical, historical, perspicacious, ontological thinking - is ever-yet 'over there'. But, for Zeno the 'relationship to place' is more basic; it is (for Zeno, and therefore and by implication Parmenides) one of the most basic ways in which being itself arises in thought. As the cointended in all thinking, it is the unthought of every thought. The true paradox of being is that it is ever-present, but not in the sense of the 'ever being' (aei on) of Plato and Aristotle, the 'constant (over-there) presence which explains presence here', but rather, in the sense of what in all presencing is also here-present. If we are to take Heidegger at his word, understanding being in this way allows us to translate Dasein, and genuinely, as 'presence'. Here Dasein, presence, would name adequately not just $m y$ presence (the way in which too many commentators have been apt to speak of 'a' Dasein) but the wherein I 'also' come to presence, alongside with all else in presencing.

This touches the most fundamental questions of thinking. It touches how Hegel and Nietzsche, in their different ways, sought to overcome the 'over there' to emphasise the 'real'. Hegel argues at one point that "it is indeed this positioning of philosophy within reality, which is struck by misunderstandings ... philosophy, because it is the getting to the bottom of the reasonable is even so the grasping of the present and real, not the erection of a beyond; God alone knows where that might be" (1986, page 24). ${ }^{(3)}$ The intrinsic relation of thinking to the forms of life that Hegel's Logic was meant to be, in its underpinning of the phenomenology of Geist, and Nietzsche's 'will to power' was supposed to name, appears in the adequate thinking of place. Nietzsche above all attempts to secure this materiality through discussion of the 'body', and much contemporary discussion has followed in this line. Embodiment as we currently discuss it, however, is devoid of the connection to place: this body thrashes around in space but never attains to the absolute unity it desires.

However, the loss of the co-intention of being, such that it must be 'recovered' through the different forms of materialism (Hegelian, Nietzschean, Marxian, and so forth), loses what it is Zeno wants us to understand cointention gives us, not that being must be 'recovered' (in 'becoming') but that being always already is, in place. Place is revealed, thought in this way, as constitutive of thinking itself, not somewhere to be got back to and into. To understand this is to understand how the 'for the same' (to auto) of Parmenides's fragment 5 can also properly be translated as 'place', topos, and even as chora (Diels, 1922, page 172). ${ }^{(4)}$

\section{Zeno's paradox}

Aristotle addresses Zeno's paradox in his Physics and refers to this as the first of Zeno's paradoxes of motion (he speaks of four), and this one, he says, "concerns not being able to be moved" because before it arrives, the thing being moved must travel to the halfway, and so forth (Aristotle Physics 239 b 11f). Aristotle dismisses the paradox

(3) "Es ist eben diese Stellung der Philosophie zur Wirklichkeit, welche die Mißverständnisse betreffen ... die Philosophie, weil sie das Ergründen des Vernünftigen ist, eben damit das Erfassen des Gegenwärtigen und Wirklichen, nicht das Aufstellen eines Jenseitigen ist, das Gott weiß, wo sein sollte" (Hegel's italics).

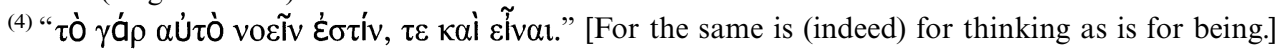


as having been "unravelled already in what was said earlier" (Aristotle, Physics 239b 13) where (in the Physics) he had dealt with the impossibility of travelling an unlimited number of indeterminate distances in limited times (233 a 20-b 15). The problem Aristotle mentions as having been earlier resolved is analogous to Zeno's first paradox because it deals with the question of how every line can be bisected on an infinite - and so unlimited (indeterminate) — series of points. The distances travelled are not unlimited in the sense of infinitely extensible but rather in the sense of infinitely divisible. The solution Aristotle proposes is therefore a logical one, one that turns on the different meanings of the infinite or illimitable (and therefore of indeterminacy). This is why it has been unravelled in what has been already said. Zeno's paradox is a 'logical' one, not a 'real' one: to understand it depends on how it is spoken of, what is to be said of it.

Aristotle proposes a proof which simply says that inasmuch as the thing moves, as the distance it traverses decreases, so the time taken to traverse the distance also decreases, thereby disproving that it will take an infinite amount of time to traverse an infinite number of distances, since, on the one hand, distance covered is proportionate to time taken and, on the other, the half is not the only possible division of the distance. There could be limitless divisions of the distance in different ways (the half is not predetermined), which nevertheless are in a sense touched by the thing covering the distance, since every distance can be divided up endlessly.

Aristotle's 'solution' is ingenious, since it turns on different ways of construing the word 'limitless', or 'indeterminate' (apeiron). However, the solution he proposes (and, in fact, every other solution I know) misses the point. The point (monas), end (telos), or limit (persas) is already presumed (and so has been said without being spoken of ) in the paradox. How is it that we know we are halfway to anywhere? Surely, because we already have the end in sight in some sense. Setting out, beginning, can only mark its passage by taking off the halfway point from having already-in some sense-reached the end and so having it in view with respect to the midpoint. The half is not measured from the beginning, but from the end, and so by bisecting the stretch that lies between the end and the beginning. In this sense it is measured from the end, as Aristotle concedes, almost without noticing he has done so, when (later) he dismisses the first of Zeno's four paradoxes of motion as a problem concerning 'the end' (Physics $239 \mathrm{~b}$ 11f). It is the direction that is given in the measuring that is critical: the measure has to be taken from the end with respect to the beginning, not the other way round. The bisection appears from the perspective of the end (even though we are not there yet); it cannot be taken from the setting-out.

\section{Zeno and Parmenides}

Zeno was (if Plato is to be believed, and we have no reason to doubt him) a disciple of Parmenides concerned with the 'all', the whole, in every case: even his name is taken from the Pythagorean term for the singular, the monadic, the unitary. A most important fragment of Parmenides's writing, Fragment $8(1-3,5-6)$, is often translated as follows: eon ... estin pan, hen, suneches - 'being is all, one and indivisible' (Coxon, 1986, page 63). The paradox is not, strictly speaking, a paradox at all: it brings to light the character of the beginning - that every beginning is 'with respect to its end' and becomes visible only because it falls out from the end, therefore taking into account the whole that is given by the beginning and the end. A similar form of this interpretation (taking the half from the end) can be found in Russell (1956, page 348), although his discussion and his account (and solution) of the paradox here is quite different from mine. A beginning is only that because it already has an end: the beginning and the end taken together disclose a unity, a whole. The paradox brings 
the end to light in a particular way with respect not to its being present but to its peculiar ability to be present in advance of itself. The paradox, as a riddle, requires for its resolution two things: one, that the end is in sight (which at the same time assembles the beginning only because beginning and end have to be copresent) and second (and more important), that there is someone for whom the end is present and has, in a sense, already been reached - if not actually, then in aim. The paradox names the disappearance of a particular kind of 'one' with respect to the end - the one for whom the end is already given and so who can take account of it.

Why a disappearance? Because when I know that the half is taken out from an end that has already presented itself in a certain way (and that means to a certain 'one', 'some' one), with respect to the beginning, there is no paradox. The paradox appears only when it is named as a general problem for 'any' one, and so an 'indeterminate' one. Who is this 'one'? Can anyone step into this place and assume it? We ask this question only from a distance, from beyond the place itself. The one himself appears in each case only because the end has already manifested itself for him; he appears from out of the beginning that the end assembles and sets forth. This is to say, no more than this one appears in a place. The place of the one in question appears and comes to be in virtue of the end, and of the beginning that the end sets out and lays open. Everyone takes place, has ends and beginnings: only the one whose end it actually is undergoes the beginning of this end and has manifest for him the end from which his beginning is taken off. Insofar as the end and beginning are mine, they are known to me 'from within', they are proper to me, and I am appropriated to them. Insofar as they are properly mine, we can call them 'ontological': they, in being given, disclose that my being has the character of a unity. The beginning, given by the end, allows me to assume the place within which my being appears and arises.

What about when one makes a beginning to which no end is in sight? This, however, is only a dependent kind of beginning - it is a way of revealing the very hiddenness of the end. It does not reveal that there is no end, but rather that the end is not yet fully known. Not known means not fully visible and yet presenting itself as a call, a demand, toward which we can be resolved or enervated.

In this sense the paradox is an ontological riddle, the solution to which depends on the one the riddle addresses and the manner in which this one receives it. Aristotle's suggestion that the paradox can be dismissed is a generalised, mathematical, or logical, answer to the riddle the paradox supplies - he takes no account of any particular end, proper to some one, but posits a calculus of all ends. Or rather, the end in question is averagely indeterminate in the same way that which the ends are to be measured against is itself always averagely indeterminate, and so 'every', actually indeterminate, end can be postulated as 'some $X$ ', from which a theoretical calculation, a mean, can be abstracted and resolved which assigns $X$ a specific value - the value of indeterminacy, which can in each case be supplied (as in, 'in this case we take $X$ as four').

\section{Greek and modern numbers}

The Greeks understood numbers somewhat differently from us. Everything that we do with numbers, they also could do (despite the claims of many modern mathematicians: much of what modern mathematicians take for granted as necessary ways of doing things numerically or geometrically the Greeks avoided simply as malpractice). Numbers, in addition to being passive heaps of things that could be counted up and divided out, also had the capacity of being powers. The Pythagoreans (of which, in a way, Plato was one) developed this to the most extraordinary degree, assigning a number to all manners of things ('being' was two, 'marriage', five). To understand how this works (and that it is not entirely fanciful) we could take the example of a mirror-glass. 
There can be a multiplicity of twos: the two-in-general (of which Plato speaks) makes more twos wherever it arises. A mirror-glass in a sense, has the power to be 'two making' (duopoios). Inasmuch as it receives an image, it repeats it. Everything placed before the glass will appear twofoldly each time.

A major difference between different schools of Greek thought is whether numbers are purely abstracted from the world (I abstract the number three from these three chairs here) or whether, inasmuch as a number can be abstracted, it can also be 'replaced' into the world in such a way that numbers explain at the most basic level how the world 'is'. Thought like this: the number 'two' explains the mirror-glass even more than the notion of what a mirror-glass is, in general, has the capacity to explain this particular glass here. The Pythagorean assignment of numbers to beings is simply the strongest form of this placing number back onto things.

A half, however, is always a division of a real number: one. Nevertheless, it also has a capacity as a kind of power - a half can be 'half-making'. Zeno's paradox could, therefore, be considered as a way of asking about what happens when the half is read back into the world as a kind of power: it will go on making halves ad infinitum, such that it will reduce everything it halves to an absurdity. In some sense this explains why the question about the paradox arises at all (else why think in these terms? - why does Zeno invent the paradox at all?). The paradox asks what happens when a half having been abstracted from somewhere is then set back on the very place from which it was abstracted. The paradox speaks about a kind of relation to the world, given through numbers - in this case numbers disclosed through the power and being of halving. It discloses a malpractice that arises when we try to force something which is asymmetrical about the world into a symmetry. This malpractice is ontological in character: as an illustration of the collapse into absurdities, it has the capacity to point us to how thinking, and thinking about the world, are connected-what kind of relation exists between thinking itself and what thinking thinks about. We see here, as the production of paradoxes, a practice of thinking that is at one and the same time obligated to world (and so not marked by the modern sense of Cartesian doubt) and characterised by necessity, the kind of necessity that arises when world is wrongly thought. Wrongly thought does not mean, however, what is wrong over and against the correct and the proper (orthos). Rather, world as it once was thought has already withdrawn, and is no longer present to call into correction a thinking that now goes astray. At one and the same time, therefore, the thinking I as obligated to world no longer has world to think and is stretching out for world's withdrawing. This means that we think rightly when we think from out of that from which world, as properly present, is withdrawn.

\section{Thinking and speaking}

Thinking is only another form of speaking - what the Greeks called logos. This means that when a number is abstracted from a number of real things, the number does not exist independently of the things in such a way that it can be said to exist prior to the things it counts. If a practice of thinking is forced back onto the world in a way that is improper or not adequately understood, paradoxes and distortions abound.

Zeno's paradox reveals itself, and its purpose, by revealing what is otherwise concealed, forgotten, or overlooked in its very concealment: for the paradox to be possible at all the journey must already have been-in one, very particular, sense at least-accomplished. Not for nothing does the paradox choose the half, the midpoint, the perfect point of division of a line. The other fractions fall out - the half of the half (the quarter), the eighth, the sixteenth, ad infinitum-only because the first appears by so easy a sleight of hand, and the division into two (our capacity to divide everything up, to slice the world into proportions and fractions which is such a proper 
and familiar activity of thinking) is so deceptively self-evident it immediately takes over and predominates. The beginning and end constitute a whole of a particular kind. It is only wholes that can be divided up. Every whole, everything that is in some sense a 'one', is at the same time as a whole, to take Parmenides's term again, suneches. Earlier we saw this word translated from the Greek as 'indivisible', but it does not mean this at all. The word comprises two parts - (sun) 'together, with' and the verb 'to have' or 'to hold' (echein). Suneches is that which holds itself together within itself: it is the 'self-holding', the continuous. As that which is held within itself, it means precisely the opposite of indivisible - it means that which, inasmuch as it is heldtogether, continues. This is the definition Aristotle gives the word sunechetai (cf Physics 227 a 13). The word suneches precisely does not denote something negative or indivisible but positive: strictly speaking, the word for indivisible in Greek is adieireton ('not divisible'), or ameristos ('not renderable into parts').

Only inasmuch as it is a whole does it appear in some sense as 'indivisible' or 'selfcontained' (suneches). If as a whole it is an indivisible, then it is the underlying possibility of every part. Every part is a part of something, something that, even in its parts, remains as a continuity, a singularity, and a whole. This is why when something is so divided up that it ceases to bear any resemblance to what it is a part $o f$, it ceases really to be a part (of that whole). The parts concerned are always parts with respect to some whole: even when we only see the parts, insofar as they are genuinely parts of something (the whole), they always indicate the whole which remains (notionally), the continuous and self-contained entity from which as parts they can be seen to be parts of a thing at all (this is why halves and fractions are not real or whole numbers).

\section{Reaching the continuous}

The word 'continuous', which Parmenides uses as the third of his descriptions of the character of being itself (after 'all' and 'one'), is also discussed by Aristotle in his Physics. Here Aristotle suggests that the 'continuous' is the most difficult of things to reach, and he names it as the last in a discussion where he is considering the character (the 'what') of the continuous in itself. He tells us that the continuous is reached by thinking through a series of determinations: "the together and the separate, and the 'what' of the touching, and the 'what' of the intermediate, and 'what' of the successive, and 'what' of the self-consistent and continuous" (Physics 226 b 18-21). ${ }^{(5)}$ This is not a simple list-sometimes the terms are paired (the together and separate, the self-consistent and continuous), sometimes the terms are simple (the touching, the intermediate). It is clear from the whole of the third chapter of the fifth book of Physics that we are required to follow through each of the determinations Aristotle gives in their particular succession if we are to arrive at the proper meaning of the continuous. Each of the earlier determinations brings us closer to the continuous until we can reach its own 'what' in its very specificity.

The significance of the list Aristotle gives is in every case to exhibit the successive stages of finding our way through the different ways in which things are parts so that we attain to the fundamental experience of the continuous. This movement is from the things which are most separated to the most continuous. Aristotle therefore invites us to see these different manners as each leading us more deeply into the continuous than the last. Martin Heidegger calls these "the phenomena of the being-with-one-another (Miteinandersein) of the things that appear for themselves" (Heidegger, 1992, page 113). ${ }^{(6)}$ This description

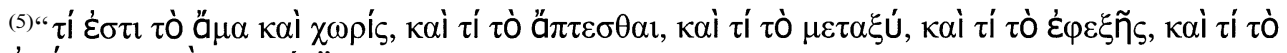

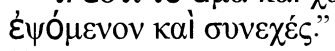

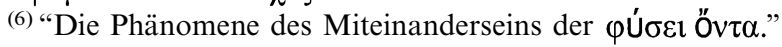


is absent from Aristotle's text, and yet it is how Heidegger illustrates what is at issue in his reading of this chapter of Aristotle's Physics. Everything (every 'one') that appears and makes itself manifest, 'the phusika' as such, appears in one or another of these ways.

Aristotle's discussion at this point in Physics intends to demonstrate that all physicalities that occur are at the same time related to being as a continuity. Heidegger warns us that Aristotle is not interested in any sort of 'theoretical construction' - this is not a 'theory', an attempt to give an abstract explanation of parts in relation to the whole as the continuous. Rather, Heidegger says, "the fundamental worth of this analysis lies in this - that Aristotle ... proceeds from that which is immediately visible" (1992, page 113). ${ }^{(7)}$ The things that are immediately visible are the things that appear for themselves. The question is not whether every kind of part is a part of being (the whole), but (in their appearing) how it is. It is here that we are required to pay the closest attention to the way in which Aristotle describes the means by which-the steps in understanding how - the continuous is disclosed. The apart and the together are the first way to understanding this: there are some things which are apart, and so in different places; others are together, and so in the same place. The things which are apart stand out with respect to their separated places. Inasmuch as the things that are apart indicate different places, the things that are together in the same place can be distinguished from them because instead of separateness they indicate 'the touching', since things that are together in the same place have to touch in order to be so.

Next in consideration is the intermediate, what lies 'in between' the things that touch. The 'in between' is one of the ways in which things may touch, by being connected by the same means. Thus one thing that changes into another could remain in the same place and is successive with what it was - the intermediate is the passage through from its having been one thing to being another, which at the same time lets the things which are together in the same place be seen as being together. In one sense the intermediate is what lets the touching touch. Aristotle gives as an example of this by speaking of musical notes from the bottom and top of a scale, referring to the smallest distance between two notes in a scale: they touch.

Insofar as what touches in the same place touches in the manner of a musical scale, thus the successive is indicated, as 'what follows on from what': one unit to the next, or one house (in a street of houses) to the next. Things can be successive because they are the same kind of thing, one after another-even though in between the succession there is something else of a different kind. Next, however, after the successive that touches, is the self-contained or contiguous, things touching without any gap in between, whose limits are right up against each other with nothing in between. Last in succession is the continuous itself - this is the very identity of the contiguous, where the limits of two things touching are in fact not two limits next to each other but the same limit, so that the two things are not defined by their limits but are distinguished by the limit itself. These things "are able to become one by touching" (Aristotle, Physics 227 a 15f). ${ }^{(8)}$ This is the continuous as such - and it is clear from all that has preceded that it is uncovered as the continuous through an investigation into the way that parts can differently be parts. Aristotle says of the continuous that it is "most of all what has the character of a coherency" (227 a 10). ${ }^{(9)}$ The word I have translated as "most of all" indicates what is most basic, most fundamental of all.

(7) "Der fundamentale Wert dieser Analysen liegt darin, daß Aristoteles gegenüber irgendwelchen theoretischen Konstruktionen ausgegangen ist von dem, was man zunächst sieht."

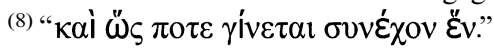

(9) " 
Aristotle is concerned with showing how we reach an understanding of the continuous as the most basic, by beginning with what is most obvious in the things that are visible - the things that lie apart in different places. But things cannot lie apart unless there is an underlying continuity to them that is in each case (even in the case of what lies apart) also there with them - the continuous. Even the lying apart depends on the successive character of places, and so of place as such. Place as such lets places be. In fact, the continuous turns out to be co-present at every step along the way to its disclosure: that is to say, without already seeing (whilst not yet knowing we are seeing) the continuous in each of the ways that parts are parts, we could never have brought ourselves into knowing that we were seeing the continuous as such. Once again, Heidegger reminds us that the conclusions of this investigation of the continuous "are the determinations of being-with-one-another" (1992, page 115). ${ }^{(10)}$

Why do we have to begin with things that lie apart, and proceed through various stages to seeing the inner unity of the things that lie apart? As with Zeno, the direction in which we think is actually the means by which we will come to understand how things are. Unless we think, without malpractice but appropriately, we will not see what is there to be seen. The continuous-because it is understood through the things that appear for themselves and so is not worked out through abstractions-also appears and is understood from out of what is and appears for itself, but even more basically. It shows itself already to have been understood in advance of every specific thing that appears; it is what lets things appear in their particularity at all. But understanding is let in to the continuous not by the continuous itself but precisely by something else-Aristotle says by the phenomenon of succession (ephexēs). So we do not see what we 'already bring to looking' (the phenomenon of the continuous) unless we learn to see how it is we look through looking at something. Looking at that something (or some things) and learning how to look at how we are looking will allow us to see for itself the manner in which we undertake the seeing that we undertake. Malpractice is excluded by self-concerned learning from self-observation of how we already are comporting ourselves. Learning is self-reflexivity with respect to the way in which things appear for themselves.

"It is evident", says Aristotle, that succession is "first in relation to the series 'succession', 'the contiguous and self-contained' and 'the continuous"” (Physics 227 a 17). (11) First in what way? Surely the continuous is really 'first' if it is most basic - it is what is always there in every particular thing, as what lets us see in all seeing? Although Aristotle argues that the continuous is the most basic in itself, something else is even more basic for understanding, something that at first hides the continuous as a phenomenon. What is more basic in understanding must also be brought to light and seen for itself as the way in to what is most basic overall.

\section{Succession and speaking}

Aristotle says, in concluding his investigation into the continuous, that succession is "first with respect to speaking" (Physics 227 a 19). ${ }^{(12)}$ This is because, although the continuous appears through all succession, Aristotle says there are those successions where ends touch and those (like numbers) which are a genuine succession but where the ends do not touch. Heidegger translates this phrase "first with respect to speaking" as "[succession] is in all denotative speech already cointended and said" (1992, page 115). ${ }^{(13)}$ Heidegger is

(10) "Das sind die Bestimmungen des Miteinanderseins."

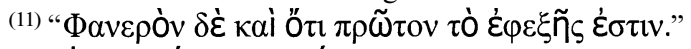

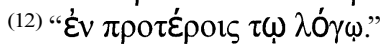

(13) " 'Es ist überall beim Ansprechen schon mitgemeint und gesagt'." 
unfolding for us how we should seek out the self-reflexive self-observation Aristotle brings to bear on this question. The issue Heidegger is trying to indicate is that speaking speaks of the continuous already having been spoken with respect to the 'denoting' of the parts: parts which are known first through succession. This is why the speech is in this sense 'denoting', addressing some part and pointing it up. Speaking is the most basic indication and activity of succession itself. Speaking is grounded in the successive (which is why language is more basic than number and arithmetic). Speaking takes for granted something prior, namely the ability to separate up the continuous, and so can only address the continuous through having already rendered it as parts. Speaking is the exhibiting of the successive, the separating up and separating out of the continuous as parts. But speaking relies on the continuous, of which it at first cannot speak, in order to be able to speak at all. Speaking gets round to speaking of what it cannot at first speak only by learning how it speaks of what it speaks and then being able to speak about its speaking. Speaking and thinking here are again to be understood as the same. Self-reflexivity is at the same time grounded in speaking.

Once we have learned how speaking speaks by dividing up, we can work out (and this means speak of) what is 'already' waiting for speaking to speak up about: the continuous. Speaking, language as such, reaches the continuous through separation. This indicates the ontological, particular, character of parts. Parts are always indicated to humanity through speaking, which means - each man, in speaking, speaks of parts with respect to the continuous. It also means insofar as there are parts, and they are understood as parts, some particular one speaker spoke them out as parts. All speaking as denotative speaking (addressing some part as a part) is with respect to the specificity of speakers - this one speaker with respect to what he is addressed by and himself speaks of.

Even more important than this, speaking speaks in relation to the unsaid (the continuous), even though in speaking we move through the successive to denote (and so speak of) the continuous. Nevertheless, speaking speaks from out of the prior unsaid, which is cointended with everything that is said.

Why is this important for Heidegger in relation to Aristotle? And why is it important for us? The successive can only count and denominate what is already here and in place-houses, chairs, numbers. If the whole is, as more basic, what lets houses, chairs, numbers, and so on be in their specificity, this suggests that the whole is also something extant and positive. This is how Parmenides has been ordinarily interpreted, as naming the whole of being as the whole of things, thingdom, as such-indeed, this is the interpretation toward which Aristotle himself is to a certain extent pressed, precisely by his interpretation of parts in their indication of the more basic whole. The whole seems to be a kind of extantness. There is therefore a kind of split between number, which as successive but not touching and so not whole, belongs solely to the intellect and only reenters the world as numbers of some things and the whole itself which 'coalesces' into the continuous as such through an analysis of the touching. Heidegger, however, wants to indicate that what is missing here is the most basic determination of the whole, the all, as such. By indicating the fundamental relation of speaking to the denotating and denominating of parts Heidegger also indicates the character of that from out of which the parts arise and into which the parts fall. Inasmuch as speaking arises on the basis of the unsaid, the all is not pure absolute presence but is characterised by a fundamental not-ness, an $a b$ sence, as what lies before and after (ie, all around) presence.

Nothing: everything arises on the basis of no-thing. Nothing here is not absolute not-ness, meaninglessness, emptiness (the perennial and silly charge that anyone who 
learns to speak of the nothing is a 'mere nihilist') but is an ontological nothing, an unknown as unseen which is in every case mine. 'Mine' does not mean 'for my use', but the other way round: it is the region to which I am already always appropriated. 'Nothing' cannot be spoken of directly, just as the continuous itself cannot be spoken of from the outset. The nothing, insofar as it can be spoken of at all, can only be learned to be spoken of. The continuous as such, which every particular whole and continuity requires to be there in order to be what it itself is, is always presupposed and givenwhich allows anything to be understood in 'being-with-one-another'. Being with one another is grounded in nothing, as what is unknown, unseen, absent, running before and after, prior to and ahead of everything. This is cogiven and actually codisclosed by the grounding of all saying in the unsaid - as Aristotle himself says.

\section{The place of speaking}

Something else is disclosed in all of this, something almost bound to be forgotten in the thinking of the modern self. Speaking is bound to the place from out of which something can be said. All speaking has, and indicates, its place. Taken in the most general sense, speaking is bound to being, and it cannot unbind itself. We will examine this necessity again, but suffice it to say here this is why when speaking comes around to revealing the continuous as what is cointended in speaking of every-thing but strictly speaking is no-thing itself, this no-thing can only be reached through the denotative speaking from places and world as such. We can only show up, disclose, and so 'denote' the continuous, the whole, because we have arrived at it through the speaking of the things that have shown themselves.

The question Zeno's paradox asks - the question Aristotle overlooks in his generalised solution to the paradox, so that even when he names the end he does not notice it - is for whom is the end in sight? There is no general calculus of ends, no method to the making and describing of ends that applies in every case: every end belongs to someone as one who speaks because the end has manifested itself and lets speaking speak. If the paradox names the difficulty that sometimes the end is in sight and at other times not (and so is denoted only in its hiddenness), then it names the fact that when the end is in sight for this one here, it might not be in sight for that one there. And again, in naming the fact that for each mortal being the end is not always in sight (because the end is concealed, it is held in the nothing), it names the ones who can see what mortals do not see-it names the gods.

The Greek gods are different to the God of contemporary theism: for the Greek gods can see what they at the same time cannot always alter (because the gods, like mortal men, are bound to fate and to the order of the cosmos) and in any case did not create. When mortals make a beginning but do not know where they are going, nor how they could separate out the 'halfway' and know that they had arrived half the way there, then they make a leap (we moderns say of faith, but the Greeks did not have a 'faith' that meant they 'believed in' their gods). They take courage that the end which is to them concealed lies open somewhere, to some one: they allow themselves to be appropriated to the hidden and unseen, the unknown, the nothing, the 'from whence' of the gods. It is here that mortal men invoked the gods or were addressed by them. Men who only sometimes have the end in view - at other times not-make in their leap that they depend at times on the gods to see what they themselves cannot see, and so that the gods should offer themselves as a guide. The gods see, and so keep, the fate of men, but they do not always dispose it: fate is prior even to the gods. For the Greeks this meant at certain times and for certain ends placing oneself in the protection or the service of a god, either overall or for particular purposes. To do this is to place oneself in the hands of one who can see in a particular way with respect to the whole, to the 
unity of the all (the nothing), when one cannot see this oneself. The god takes the place of the end (which is not in sight). The fate in question is the binding character of being, such that we cannot escape or evade or elude the place from which we speak. Fate (moira) names no more nor any less than this.

Put another way, this shows me that my self is a kind of part of the whole, as well as a whole in itself. And it makes even the gods ones who are 'with respect to' the whole, because even if they can take in the whole all at once and have it in view, even they cannot always alter what they know. It becomes clear therefore why for the Greeks certain men and women, and certain tasks, certain fates, and certain punishments and joys belong to particular gods. They are the ones who see most or best with respect to that character of the whole. The dwelling of the gods is not in any place but in the concealed, the nothing. The gods are without place. The gods come from no where to enter places. Their 'from whence' always and each time is a coming out that takes place anew.

If Zeno's paradox names our being with respect to the whole, that is in the being of our being such that both the beginning and the end are present, and through that being-present the being of my being also becomes present-the whole in question is only a particular whole. The particularity of the whole indicates something further, that this whole here is taken off from the whole as such, the whole that lies prior, and is held in no-where and by no-thing. Plato calls this the 'third kind' (genos triton) of thing within which every other must appear (Plato, Republic 507 D 508 A). The whole-in-all, wholeness as such, is always present, and indicated, in every particular singular thing or place, every integral unity or whole that appears. In drawing attention to Zeno's understanding of the continuous, Heidegger notes that "While Zeno's arguments are indeed negative in form, yet upon closer inspection they however bring being out into sharper relief. The continuous is a phenomenon that lies equally at the basis of magnitude, space, and common time" (1993, page 76). ${ }^{(14)}$

Insofar as the whole, in appearing and being taken off, in its being-taken-off, can also be rendered into parts; what the paradox primarily indicates is that the particular whole indicates the whole-overall (the continuous, the nothing) at the same time, by indicating that the beginning and the end, self-contained and continuous, arise from and emerge out of (are taken off from) the whole as such: the beginning and the end are grounded in the whole-nothing. If we take Parmenides's fragment 'being is all, one, and continuous', we see that Zeno's paradox, as it becomes ontologically available to us (as I myself arise on the basis of what I know in what I know), allows me to traverse Parmenides's fragment in reverse. Through the divisibility of every appearing of an end, such that it is not yet reached, I am within the traversal, self-reflexively, not outside, not onlooking. I encounter indivisibility, and continuousness, and I do this through an already given understanding of belonging in the nothing.

Inasmuch as the whole is not given and is not coindicated, the paradox collapses into absurdity - as not even really a paradox. In fact, its whole meaning disappears, and we are left wondering why it appears as a question at all. Insofar as the whole is given and the nothing becomes available to us (as the unsaid in every saying), and its ontological meaning is disclosed, not only does it reverse itself through the order of being that Parmenides also names, but in fact it discloses a further meaning: that of the way in which the end itself is formally attractive; it pulls us to it. Exactly as in the average, unwholesome, un-self-discovered version of the paradox, we can never set out from the beginning, so as soon as the specificity of the whole given and from out

(14) "Zugleich die Argumente des Zenos in der Form zwar negativ, aber doch bei näherem Zusehen

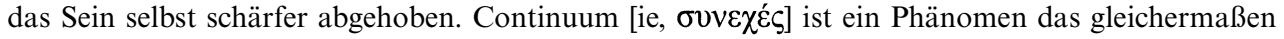
Größe, Raum, vulgärer Zeit mit zugrunde liegt.” 
of which I also appear for myself, so we cannot escape from the ever-strengthening realisation of the end itself. The end manifests itself in ever-increasing magnitude until it is fully arrived at.

Being within the traversal of the passageway across by taking the beginning from out of the end is, as Aristotle has indicated to us in his phenomenological investigation of the twin phenomena of the continuous and the successive, essential to a certain kind of experience of the whole simultaneously appearing through parts: $I$ emerge as coconstituted by the beginning and the end; my emerging is at the same time my belonging to the all-ness of the whole as such. I take place in time. I am not apart, nor merely a part, but given in and through the parts in their simultaneous belongingtogether with each other. My own unity is disclosed through the traversal. This has a further consequence, one essential both for my self-understanding and for understanding my being in the world and the being of the world in itself. Inasmuch as I myself am a whole, I am analogous to the whole, but I am a whole within this whole. Inasmuch as I encounter the whole through denotating the succession and manifestation of its parts, the whole also gives itself. Inasmuch as I encounter my wholeness-within-thewholeness-of-the-all, it is an encounter through the parts of the whole. Ontologically speaking: the parts are not anterior or posterior to the whole; the whole is not anterior or posterior to the parts. Inasmuch as I know, I at the same time know the whole in the manner of its appearing and the parts in the manner of their separating out.

\section{For the sake of continuity: conclusion}

As continuous, the end and the beginning are continuous and held together such that they appear as a unity (hen), which itself indicates and is analogous to the all: the 'all' is the ever-continuing. This is not a continuity stretched out to infinity - for the Greeks, the circular is both the highest form of motion and the highest form of a plane. As continuous, it is ever-connected with itself and returns to itself - it has no beginning and no end and yet is not defined as infinite stretch or extension (as space is by Descartes or Newton). Zeno's paradox is therefore a way-in to the being of beings itself, grounded in the nothing, but one in which we have encountered ourselves, taken each by each, as one addressed and who, in encountering both the beginning and end, appear from out of the end in its uncovering of the beginning.

Through dissolving the paradox, the all, the whole as such has appeared, the whole which Parmenides names with the word 'being' (on in the more ancient form eon). Every particular whole indicates, and at the same time is drawn off from, the all as such. Every particular whole indicates, and as such lets appear, the one that I am. What has appeared is the phenomenon of world as such. Not any particular world, the world of 5th-century Elea, or contemporary London. In the taking off of beginnings and ends, world 'worlds'. It worlds for me. Inasmuch as I understand this, it is binding for me; it is the most binding.

Is this where we should really begin? Should we not better begin not by trying to get the whole in sight but by taking account of where we are and who we are? Who do we think we are? For the Greek gods have been long in flight, and succeeding them the God of theism, of Abraham and his children, arose, and even this God is now, it seems, well on the way out. How could our world have come to be so different to that of the Greeks?

Why does Zeno announce what he has to say in paradoxes and riddles? Diogenes Laertius, keeper of so much of the gossip of antiquity, attributed to Aristotle the view that Zeno was the first to discover dialectic (inasmuch as Empedocles was first to discover rhetoric). If Zeno is indeed a dialectician, I want to suggest he is one of a most peculiar kind: one who, through his dialectic, is trying to show us that we have 
become blind. How do you see that you can no longer see? Would such an effort not be the attempted gift of the restoration of sight-or restoration of our need of it? Is it not that Zeno wants us to see that we have become blind with respect to place, the place wherein we always are?

\section{References}

Booth N, 1957, "Zeno's paradoxes" The Journal of Hellenic Studies 77 187-201

Cajori F, 1915, "The history of Zeno's arguments on motion: phases in the development of the theory of limits" The American Mathematical Monthly 22 i-315

Cajori F, 1920, "The purpose of Zeno's arguments on motion" Isis 3 7-20

Coxon A H, 1986 The Fragments of Parmenides (Van Gorcum, Maastricht)

Diels H, 1922 Die Fragmente der Vorsokratiker volume 1 (Weidmannsche Buchhandlung, Berlin) pp $165-175$

Hegel G W F, 1986 Grundlinien der Philosophie des Rechts oder Naturrecht und Staatswissenschaft im Grundrisse edited and translated by T M Knox Hegel's Philosophy of Right (Oxford University Press, Oxford) 1973 (1952)

Heidegger M, 1992 Platon: Sophistes edited and translated by R Rojcewicz, A Schuwer Plato's Sophist (Indiana University Press, Bloomington, IN)

Heidegger M, 1993, "Die Grundbegriffe der antiken Philosophie", in Heidegger Gesamtausgabe volume 22 (Klostermann, Frankfurt)

Lee H D P, 1936 Zeno of Elea (Cambridge University Press, Cambridge)

Papa-Grimaldi A, 1996, "Why mathematical solutions of Zeno's paradoxes miss the point: Zeno's one and many relation and Parmenides' prohibition", in The Review of Metaphysics 50299 - 314

Quan S, 1968, "The solution of Zeno's first paradox" Mind, New Series $77206-221$

Russell B, 1956 The Principles of Mathematics (Allen and Unwin, London)

Sherry D, 1988, "Zeno's metrical paradox revisited" Philosophy of Science 55 58-73

Solmsen F, 1971, "The tradition of Zeno of Elea re-examined" Phronesis 16 116-141

Vlastos G, 1975, "Plato's testimony concerning Zeno of Elea" The Journal of Hellenic Studies $95136-162$ 
Conditions of use. This article may be downloaded from the E\&P website for personal research by members of subscribing organisations. This PDF may not be placed on any website (or other online distribution system) without permission of the publisher. 